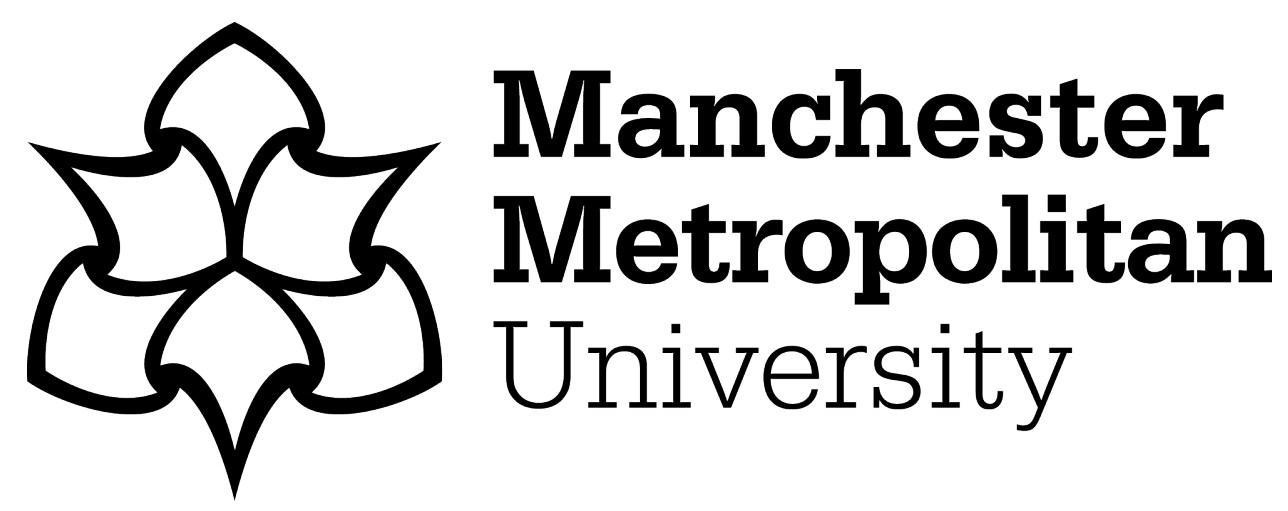

Shi, Charlotte, Warnaby, Gary ORCID logoORCID: https://orcid.org/00000002-6696-6671 and Quinn, Lee (2021) Territorialising brand experience and consumption: negotiating a role for pop-up retailing. Journal of Consumer Culture, 21 (2). pp. 359-380. ISSN 1469-5405

Downloaded from: https://e-space.mmu.ac.uk/623017/

Version: Accepted Version

Publisher: SAGE Publications

DOI: https://doi.org/10.1177/1469540519889996

Please cite the published version 
Territorialising brand experience and consumption: negotiating a role for pop-up retailing

Charlotte Shi, Gary Warnaby and Lee Quinn

Contact details:

Charlotte Shi

Manchester Airports Group, 5th Floor, Olympic House, Manchester Airport, M90 1 QX, United Kingdom. Email: Charlotte.shi@magairports.com.

Gary Warnaby (Author for Correspondence)

Institute of Place Management, Faculty of Business and Law, All Saints Campus, Oxford Road, Manchester Metropolitan University, Manchester, M15 6BH.

Email: g.warnaby@mmu.ac.uk Tel : +44(0)161 2473847

\section{Lee Quinn}

Centre for Business in Society, Faculty of Business and Law, Coventry University, Priory Street, Coventry, CV1 5FB. Email: lee.quinn@coventry.ac.uk 


\title{
Territorialising brand experience and consumption: negotiating a role for pop-up retailing
}

\begin{abstract}
The evolving consumption landscape creates challenges for retailers in accommodating their modus operandi to negotiate changing consumer needs, arguably requiring a 'new' type of retailing to hopefully facilitate future success. We suggest that an important aspect of such negotiation will be the use of 'pop-up' activity, and we critically evaluate the potential of these ephemeral consumption spaces to constitute and shape consumers' brand-oriented relations and experiences into the future.

Informed by the work of Deleuze and Guattari, we take a territorological perspective. Drawing on data from eight UK-based pop-up cases, we analyse: (1) how these temporary 'territories' of brand experience are developed and implemented; (2) what differentiates them from other, traditionally conceived, territories of brand experience; and (3) critically evaluate pop-up's neglected characterisation in terms of a more 'fluid' spatial-temporal retail territory, to better understand its role in contemporary consumer culture.

We posit that the development of pop-up activities occurs through the coordination of actions of a variety of stakeholders, constituting a spatial-temporal confluence of both material and processual elements to create a 'refrain', through the compression and compaction of interior, intermediary, exterior and annexed milieus. In doing so, we offer a new lens through which to view the creation of retail consumption spaces.
\end{abstract}

Keywords: pop-up; retailing; territory; brand experience; milieu 


\section{Introduction}

More nuanced, interdisciplinary theorisations of space and place, incorporating phenomenologically oriented, social relational perspectives - and a more overt consideration of temporality - are arguably required in relation to sites of marketing/consumption (Chatzidakis et al.: 2018). In a consumer culture context, one recent practice that potentially provides a fertile ground for investigations into such issues is the 'pop-up' concept, which has been embraced by an array of commercial and non-commercial organisations (Ferreri, 2015). Pop-up is especially evident in retailing (see Warnaby and Shi, 2018), and has become "a fashionable choice for creative start-ups and a popular marketing tactic for global brands" (Harris, 2015: 592).

From a business/marketing perspective, Warnaby et al. (2015) identify three distinguishing characteristics of pop-up retailing: (1) an experiential in-store environment facilitating consumer-brand engagement; (2) a focus on promoting a brand/product line to create a 'buzz'; and (3) presence for a limited period in order to create a sense of urgency, and stimulate purchase or other action. From a geographical perspective, in a broader urban context, Harris (2015: 593) identifies three "significant spatiotemporal imaginaries" of pop-up: (1) Flexibility - i.e. "where pop-up valorises places which are quick to construct, relocate and remove, organising space-time to assure its plasticity in the future"; (2) Interstitiality - i.e. relating to the spatiotemporal in-betweeness of pop-up locations; and (3) Immersion - i.e. emphasising pop-up's experiential attributes.

Accordingly, pop-up invites us to understand socio-relational, spatial, and temporal elements of retailing as a departure from the widely-conceived, bounded and physical sites of consumption exemplified by fixed retail formats, through which traditional accounts have largely been theorised (e.g. Puccinelli et al., 2009; Verhoef et al., 2009). The possible implications of these more ephemeral settings of consumer-brand interactions (usually in an 
urban context), are wide-ranging and significant. For, example, the branded space of pop-up stores could be conceptualised as a manifestation Moor's (2003) 'new marketing', revolving around brand communities of interest, characterised by spatial-temporal flexibility and an overtly experiential orientation to create a brand-oriented 'space of proximity' for consumers. Recent industry developments - notably the rise of online consumption and its concomitant impact on 'traditional' retail space, in terms of how it is perceived and used (see Butler, 2018; Wood, 2017, for recent press comment on this issue, and from a broader academic perspective, Ritzer and Miles, 2019) - means that such 'spaces of proximity' in a retail context are increasingly manifest across both 'real' and virtual space, and time. Thus, the consequent need for retailers to be flexible in order to succeed - or, indeed, merely survive - in an increasingly multi- and omni-channel industry has arguably never been greater.

In a broader urban context, taking a rhythmic spatial-temporal perspective, Madanipour (2017: 50-51) notes that there will inevitably be periodic mismatches between spatial supply and demand. This is evident in the cyclical nature of the market economy, "reflected in the periods of expansion and contraction, which are accompanied by a parallel process of spatial production", which has "created spatial, temporal and institutional gaps, which are sometimes filled by temporary interventions, in search of interim solutions". The temporary nature of pop-up is reflected in its descriptions as 'interim' and 'meanwhile' uses of urban space (Ferreri 2015), and as urban 'interruptions', appropriating space in novel and potentially innovative ways for a limited period (Ferreri, 2016). Thus, Harris (2015: 598) argues that pop-up, by filling up - or 'papering over' - gaps in urban spatial production, "reframing it as an opportunity for immediate use and future development", thereby perpetuates the old order during times of urban crisis, which will revert to 'normal use' when the crisis passes. Indeed, such spatialtemporal flexibility becomes "a valuable urban model" (ibid: 594) in that it reduces economic risk in times of uncertainty, as well as generating capital flow for property owners that would 
otherwise not be realised, in addition to promoting innovation. However, Harris also highlights the existence of a downside to such flexibility; namely precarity, both of place (i.e. pop-up places are provisional and temporary), and also of labour (in that there is an assumption that those employed in pop-up are also exhibiting total flexibility, manifest in precarious or intermittent employment - see also Ferreri, 2015).

This leads to questions relating to the extent to which retail space needs to be (re)conceptualised in more flexible terms, in order to reflect its ever more fluid and relational nature. In our research, we investigate the potential of the pop-up concept in this regard, drawing on the concept of territorology (Brighenti, 2010) in the context of the pop-up retail store, which we suggest can be considered a 'territory'.

Initially, it may seem counter-intuitive to consider pop-up, characterised by its inherent flexibility, in this way; partly because 'territory' has been traditionally imagined, from a 'sedentarist' perspective, in terms of fixity and enclosure (Brighenti, 2014), and as a distinct, boundaried space affected by a certain control or regular set of behaviours (see Kärrholm, 2007, 2012, for a review). However, it is important to recognise that territory can be regarded as "not an absolute concept. It is always relative to a sphere of application or a structural domain of practice" (Brighenti, 2010: 61). Territories, thus, arise through (possibly contested) processes of producing, maintaining and assigning spaces with meaning (Kärrholm, 2007, 2008). In other words, a territory is a product of human and institutional relations. Indeed, counter to some stereotypical perspectives, Brighenti (2010: 53) argues that territory is "better conceived as an act or practice rather than an object or physical space", suggesting that the main characteristics of territories can be considered from more dynamic relational and processual perspectives. Thus, "[f]ar from being the epitome of fixity, territories are on-going, open productions" (Brighenti, 2014: 15). We thus argue that conceptualising the inherent flexibility of pop-up retailing through the lens of territorology helps us analyse how this manifestation of, to adapt 
Moor's (2003) term, this 'new retailing' can more fully address the needs of the changing contemporary landscape of consumer culture.

We begin by reviewing the literature on territory, noting the significance of, and framing a particular emphasis on, Deleuze and Guattari's (1987) notions of refrain and milieus, and outline the empirical suitability of pop-up activities for the purposes of our inquiry. Drawing on data relating to the development and implementation of eight case studies of UKbased pop-up retail activities, perceived as successful by those who developed and implemented them, we analyse how these spatially and temporally flexible 'territories' of brand consumption can be elucidated. More specifically, using the 'refrain' as a guiding conceptualisation, we seek to address the following research objectives:

(1) To establish how these temporary, flexible territories are developed and implemented;

(2) To evidence what differentiates them from other, traditionally conceived, territories of brand experience.

These initial objectives enable us to address our final objective, which summarises the broader contribution of our research:

(3) To critically evaluate pop-up's neglected characterisation as 'fluid' spatial-temporal retail territories, to better understand its role in contemporary consumer culture.

\section{Locating a territorial perspective on pop-up retailing}

A fundamental aspect in defining (and delineating) territory is the role of boundaries, which "become the object of an on-going work of enactment, reinforcement, negation, interpretation and negotiation" (Brighenti, 2010: 62), making the creation of territory an active and dynamic endeavour (Kärrholm, 2009). Drawing on Deleuze and Guattari (1987), Brighenti suggests that, "a territory is not to be understood as an object, nor as a subject, but rather as a mode, or act", 
through which 'territorial movements' (incorporating deterritorialisation, reterritorialisation and territorialisation) can be viewed as "a way of expressing a certain relationship with the world" (2010: 63-64).

Deleuze and Guattari (1987) use a musical analogy to express this relationship, through notions of rhythm (conceptualised in terms of territorial motifs, characterising the specific expressive qualities of a space), and melody (i.e. territorial counterpoints, which express the relationship between territory and external circumstances). They describe the coming together of rhythms and melodies in an expressive manner to create a territory using the term refrain. We posit that experiential and spatially-temporally flexible pop-up territories (often, according to Pomodoro, 2013, considered as events), can be conceptualised as refrains; namely, the confluence of material and processual (incorporating notions of 'territorial movements') elements, at a particular place and time.

In the pop-up retail context, a territorial motif could relate to those elements (e.g. logo, design concept, store fixtures/fittings etc.) that identify the brand, whereas a territorial counterpoint serves to contrast the brand with its surroundings, thereby assuming territorialising properties. Deleuze and Guattari further argue that territory "is built from aspects or portions of milieus" (1987: 314), having interior, intermediary, exterior and annexed milieus.

The milieu concept can be usefully applied to pop-up retailing. Thus, the interior milieu could constitute the in-store environment (i.e. the materiality of the store design, fixtures/ fittings etc., thereby helping create 'motifs'). Pop-up's essential ephemerality means that its ‘material stabilisation' (Kärrholm, 2008) needs perforce to be flexible (see de Lassus and Anido Freire, 2014), facilitating ease of movement, and assembly/dismantling etc. The intermediary milieu arguably constitutes the location of the pop-up store in its immediate environs, and thereby, creating boundaries, which may be manifest in both material and 
performative ways. This provides a counterpoint to the wider external - usually urban - milieu within which the store is located, and indeed, some classificatory schema of pop-up stores explicitly use the type of area within which a store is located as a distinguishing criterion (see Surchi, 2011). The annexed milieu arguably relates to the fact that, "the lines between pop-up and traditional retailing are fading fast" (CEBR, 2015: 4). Thus, retail experience is not restricted to the physical territory of the store, but increasingly incorporates a related digital experience in 'alternative channels' (Verhoef et al., 2009).

In spatial terms, this notion of milieus provides a useful explication of pop-up retailing. In temporal terms, this incorporates an 'evental' (Brighenti, 2010) perspective, and the associated consumption experience can be viewed processually (Antéblian et al., 2014; Tynan and McKechnie, 2009). This can involve multiple touch-points and require substantial interaction between the parties organising the activity, and the wider brand community (Arnould et al., 2004, and in this specific context, Klein et al., 2016), thereby resonating with the notion of pop-up activity as 'refrain'. We now turn our attention towards the means by which we addressed our research objectives.

\section{Research design}

The empirical material presented is drawn from eight pop-up case organisations (see Table 1) enabling the study of "a number of cases in order to inquire into the phenomenon, population or general condition" (Stake, 1998: 89). This approach was chosen because of its suitability for examining different features of a relatively new phenomenon [pop-up retailing] and the relationship between them (Eisenhardt, 1989). We identified case examples by following an established conceptual approach for positioning different retail types in terms of two key dimensions, represented as continua (e.g. Sherry, 1990). We therefore position our cases according to: 
(1) The purpose of the pop-up activity, distinguishing between transactional and promotional;

(2) The nature of the organisation, distinguishing between emergent brands (i.e. operated by entrepreneurs, which are at the earliest stages of their life-cycles), and established brands.

This guided our conceptual interpretation of the retail context (see Figure 1) to inform case selection.

Insert Table 1 about here.

Insert Figure 1 about here.

Given the focus of the inquiry to interrogate and critically evaluate the potential of these ephemeral consumption spaces to constitute and shape consumers' brand-oriented relations and experiences, a mix of qualitative methods was chosen (Hracs and Jannssen, 2017). The primary source of data collected included sixteen semi-structured interviews (typically lasting around 60 minutes) with brand founders, senior managers, PR, marketing and event managers, and store staff as appropriate to each case. Consistent with the experiential marketing literature (e.g. Antéblian et al., 2014, Tynan and McKechnie, 2009), interviews were structured chronologically, to investigate decision areas and activities undertaken within three processual stages - pre-pop-up activity, actual pop-up activity, and post-pop-up activity - as well as investigating the motives behind the decision to use a pop-up concept. In addition, nonparticipant observations during pop-up events were captured in field notes alongside electronic content generated through retailers' social media feeds, while other artefacts, such as promotional materials, collected during the lead researcher's time the field, were gathered in 
order to supplement subsequent analysis. Such 'data triangulation' (Denzin, 1978), involving the use of a variety of data sources in a study, "opens the way for richer and potentially more valid interpretations" (Decrop, 1999: 159). In particular, the field notes were especially useful in supplementing interview data by shedding "additional light on the textual content" and identifying themes (Decrop, 1999) by which we structured our interpretive account. Following an established process of thematic coding (Crang, 2005; Hracs and Janssen, 2017) - where themes were drawn from the chronological structure of the interviews (consistent with the experiential marketing literature described above), and additional themes identified from the supplementary information sources - the analytical procedure was emergent and iterative, allowing us to move back and forth between the literature, data collection and interpretation in order to identify and organise findings relating to the material (incorporating interior, intermediary, exterior and annexed milieus), and processual elements (incorporating territorial movement and temporality); combining to create the refrain which constitutes the pop-up territory. In our findings, we present this as the narrative basis of our interpretation in order to maintain a sensitivity to the underpinning theorisation of territory. Through this approach, "the theory-building process occurs via recursive cycling among the case data, emerging theory, and later, extant literature" (Eisenhardt and Graebner, 2007: 25), as we sought to inform our research concerns "about how social experience is created and given meaning" (Gephart, 2004: 454). In order to maintain sensitivity towards issues of unitisation and intercoder reliability and agreement (Campbell et al., 2013), and consistent with Denzin's (1978) notion of 'investigator triangulation', the final themes through which we present the narrative basis of our interpretation were refined following a number of iterative discussions between the researchers focusing on the material and temporal dimensions of pop-up.

\section{Findings}


Our findings are divided into three main sections relating to: (1) material and spatial aspects; (2) processual elements; and (3) negotiating pop-up's potential role in the contemporary landscape of consumer culture. Here, we draw on the notion of refrain, conceptualising territory as a confluence of material and processual elements at a particular place and time, and which Deleuze and Guattari (1987) highlight as having a catalytic function.

\section{Material and spatial aspects: constituting pop-up territories}

The first research objective relates to the means by which pop-up territories are developed and implemented. We structure this account using the milieu concept, to discuss how pop-up territories can be conceptualised through interior, intermediary, exterior and annexed milieus.

\section{$\underline{\text { Interior milieu }}$}

The interior milieu refers to "composing elements" and "composed substances" (Deleuze and Guattari, 1987: 313), which in the pop-up retail context, can comprise specific design concepts, configurations of corporate identity elements, fixtures and fittings etc. affecting consumer experience. This resonates with existing conceptualisations of more traditional fixed retail formats as an important medium for consumer experience creation (e.g. Verhoef et al., 2009), but acknowledges that modification/accommodation to the temporary nature of the space is an important aspect of planning store atmospherics in this context. Some retailers under study kept the original configuration of the available space for the pop-up, especially if perceived to reflect brand values (see Overdiek, 2018), also recognising that design standards and atmospherics could be more flexible in this temporary context (de Lassus and Anido Friere, 2014):

"It was an existing building, but actually, to be fair, we didn't do a huge amount inside... we weren't trying to pretend we were anything but we were popping up for a limited 
period of time in these environments" (Brand Concept Manager, Department Store Chain).

Moreover, some interior milieu elements are expressive in that they nurture, enhance and entertain relations, which in turn, constitute territorial motifs (Deleuze and Guattari, 1987) relating to the brands in question. Thus, in some of the pop-up stores investigated, the presence of multiple screens, allowing the controlled communication of promotional messages, was observed. This was also a means of overcoming some inherent space constraints. For example, it was observed that the spatial 'footprint' of various pop-ups was relatively small - as one respondent noted, "There is not a huge amount of space to do "big display"'. It also facilitated spatial flexibility within the interior milieu. For 'nomadic' pop-ups moving from location to location, such as the Online Women's Clothing Brand that occupied empty premises in four UK cities, this could be regarded as a means of more effectively accommodating brand related territorial motifs to the actual topography of the available space. This was of particular importance given the fact that some respondents articulated difficulties in obtaining empty premises, with numerous examples cited of space suddenly becoming unavailable, requiring the company to amend their existing plans for the design of the interior milieu

\section{Intermediary milieu}

The intermediary milieu denotes the 'membranes' that limit and mark the territory (Deleuze and Guattari, 1987), established by, among other things, actants (e.g. artefacts, rules etc.) that work together in networks to enable those within to perform particular activities or functions, and in so doing contribute to territorial creation, and moreover, development of counterpoint (i.e. the relationship between territory and external circumstances). 
Thus, in a pop-up context, this intermediary milieu can be manifest in the adoption of an accepted mode of behaviour (especially within more interactive/experiential pop-ups). Other performative aspects could include the need to register interest (e.g. via response to social media stimuli prior to a visit), or booking tickets to gain admission. Furthermore, this performativity can contribute to the creation of a community of practice centred on the brand (Surchi, 2011). The space of the Online Menswear Retailer emphasised these performative aspects, planned as a live-performance installation, incorporating production, design and consumption, which offered customers a high degree of transparency, and built a human narrative into the production process:

'I've quite enjoyed gauging people's responses to the fact that we're making stuff instore.... It has been a nice way to engage with people" (Brand Founder).

As Brighenti (2010: 57) notes "only once relations among actors, rather than space, are put at the conceptual core of territory, does it become possible to capture the ways in which spatial and non-spatial territories are superimposed on one another and endowed with multiple meanings". Performativity may, therefore, be underpinned by the material elements of the interior milieu and the topography of the space, reinforcing Deleuze and Guattari's argument that one milieu serves as the basis for another, and that they are essentially communicating between each other. Where pop-ups occupy existing vacant retail premises their boundaries have an obvious materiality, but for Lifestyle Fashion Brand (which was part of a pop-up 'department store' also incorporating other brands, and where boundaries between brand spaces were much more porous), observation highlighted the importance of performativity and actants in territorial creation, as reinforced by the Brand Founder: 
"It is very difficult to come up with the visual format that allowed us to communicate our own identity within the external environment [of the pop-up department store]. I think that was the biggest challenge of the last 10 days".

\section{$\underline{\text { Exterior milieu }}$}

In this context, the exterior milieu refers to the interaction between the pop-up shop and the surrounding built environment, again resonating with the notion of counterpoint. Thus, the fact that a particular space is colonised for the duration of the pop-up activity (by actants and performative expressions), will serve to frame the territory and distinguish it from 'outside'. Most cases under study used dedicated agencies to secure pop-up venues, and as mentioned above reported that finding appropriate locations as occasionally problematic.

Russo Spena et al. (2012) state that central, high-traffic urban shopping districts are very popular among pop-ups, to ensure visibility. This is evident here, particularly in the cases featuring online retailers. For example, the choice of pop-up location for the Online Women's Clothing Brand was based on where its existing customers were concentrated. Others located pop-ups in locations to reach new clientele, and the Department Store Chain opened its pop-up store prior to the opening of a permanent store in a provincial city, to increase local brand awareness.

Indeed, for all the retailers under study, respondents articulated that access to their actual or potential customer base was, understandably, a crucial fact in determining the choice of location for the pop-up activity. This was borne out by observational data of the immediate environs of the pop-up stores, which, whenever possible, were located amongst other retailers also appealing to the target customer. This resonates with some of the perceived advantages of the retail agglomeration concept (see Brown, 1987) and can be regarded as a prudent strategy if the aim of the pop-up up is primarily 'communicational' (Warnaby et al., 2015) in terms of 
raising awareness etc. More specifically, when seeking to raise awareness of an essentially ephemeral retail outlet, then time is of the essence, and locating in areas the maximise footfall is a logical strategy. In the current retail industry environment, characterised by locational retrenchment (as mentioned above), then some of the difficulties in finding suitable space for pop-up activities mentioned by respondents might be minimised into the future.

\section{Annexed milieu}

The annexed milieu (conceived in behavioural terms, according to Deleuze and Guattari, relating to 'action-perception'), can in this context refer to the blurring of the distinctions between pop-up and traditional retailing (CEBR, 2015), and pop-up's interaction with other activities consistent with the broader concept of multi-channel retailing. As part of the experiential elements within the interior milieu of the store, observation data indicated that innovative technologies and digital installations played an important role in territorialisation for the majority of the cases under study, as mentioned above. However, this was evident beyond the physical territory of the internal, intermediary and external milieus; manifest, for example, in systems enabling consumers to access the brands through interactive interfaces (Pantano and Viassone 2014). As the Founder of the Lifestyle Fashion Brand stated:

“... when people walk in [to the pop-up shop] they can socially interact with our atelier [located in another country]... we want people to understand our ideas, our interests ... it is really a marketing tool to show who we are."

Linking to Brighenti's (2010) notion of territory, as defined as much by performativity as spatiality, the pop-up territory can be expanded (both spatially and temporally) into the annexed milieu via, for example, social media channels; by sharing and posting images arising from the event to create a sense of broader brand community among consumers. Thus, the 
Cosmetics Company's mobile app enabled guests to book appointments and reserve bar tables at the pop-up store, share photos and access live social media news feeds irrespective of their location. This also facilitated evaluation by the company:

“...with the app we are driving everything from one platform which gives us great measurability, as well as a great experience for our customers" (Head of PR and Events, Cosmetics Company).

This reinforces Deleuze and Guattari's argument that functions in a territory are not merely 'primary', but also presuppose a territory-producing expressiveness. This potentially becomes multi-dimensional: connecting the material with the immaterial (Vandenberghe 2007), virtual and physical, thereby extending the consumer's temporal brand experience both before and after the pop-up, creating ongoing communities of interest (Moor, 2003).

\section{Processual elements: territorial movement and temporal considerations}

Territories can be delimited by both physical and relational boundaries (Brighenti, 2010). Consequently, they may not be totally 'fixed' entities, but created through the 'synchronisation' of different rhythms (Kärrholm, 2009), via processes of de- and re-territorialisation, coalescing at particular times and spaces to create 'refrains'. The overtly processual (and temporal) dimension this implies distinguishes pop-up from more 'sedentarist' (Brighenti, 2014) territories of fixed retail stores.

Turning our attention towards addressing the second research objective, we now consider what differentiates pop-up territories from other, traditionally conceived territories of brand experience.

\section{$\underline{\text { Territorial movement }}$}


As seen in Table 1, the pop-up activities under study had varying durations. Indeed, as the Founder of the Wine Tasting Company suggested: "We keep moving about to different venues, doing different tasting events and that was partially choice, partially necessity". Pop-up's essential ephemerality recalls the concept of 'territorial movement' (Brighenti, 2010) resonating with Deleuze and Guattari's (1987) notions of de- and re-territorialisation, with popup activities assembled and dismantled in situ as appropriate. This is especially true of 'nomadic' pop-up stores, where there may be greater freedom to determine the spatiality of the territory, contingent upon restrictions posed by the particular nature of the store format - e.g. shipping containers re-purposed as pop-up stores (see Beekmans and de Boer, 2014; Schwarzer, 2013), which itself constitutes another specific manifestation of de- and reterritorialisation.

Drawing on notions of assemblage, Deleuze and Guattari (1987) argue that a territory is always en route to an - at least potential - de-territorialisation, even though in this process the creation of a new assemblage may in turn constitute a re-territorialisation. For example, fixtures and fittings in pop-up stores may be explicitly designed to increase flexibility (de Lassus and Anido Freire, 2014), especially in relation to performativity, resonating with notions of territorial 'movement'. Thus, an important consideration in the design of the Bicycle Brand's pop-up store was to ensure a smooth switchover between physical shop and event space at different times. Wooden crates (associated with the notion of travel and adventure, consistent with the company's brand values) were used to display bikes during the day, and were then separated and used as seats for guests during evening talks/events. As Melewar (2003) suggests, specific designs, fixtures and fittings communicate and reflect the corporate identity; here creating an (albeit transient) brand territory for the Bicycle Brand.

De- and re-territorialisation is of particular resonance with the nomadic pop-up store, which is in an almost perpetual state of material de-and re-territorialisation. These processes 
can be regarded as "a series of unclaspings" (Deleuze and Guattari, 1987: 326), which will affect the various milieus discussed above. Thus, some of the key fixtures and fittings of the Cosmetics Company's London pop-up were transported in a shipping container, recreating the experience in four UK cities, thereby increasing the brand's spatial reach:

"...it was important for us to spread out the experience across the country. We firstly located the key territories, and then literally packed everything up that was in the [London] venue and put it in the container and took it on tour" (Event Manager).

\section{$\underline{\text { Temporal considerations }}$}

If the optimum benefits are to be realised, then pop-up 'events' need to be planned and managed. Arguably, the synchronisation of all the material elements in each of the milieus outlined above, coupled with finite timescales arising from pop-up's inherent ephemerality, make planning and implementing pop-up activities more complex than would be the case for more sedentary, fixed retail formats.

In the event management literature, generic schemas have been developed which adopting an overt temporal perspective - incorporate processual stages of analysis, planning, implementation and evaluation (e.g. Bladen et al., 2012; Donlan and Crowther, 2014; Tum et al., 2006), and arguably constitute the means by which 'territorial movement' - which Brighenti $(2010,63)$ regards "as a mode, or act" - is operationalised. This resonates with the ways in which consumer experience(s) have been conceptualised in processual terms, constituting different temporal stages (see Antéblian et al., 2014; Tynan and McKechnie, 2009). From a brand management perspective, this incorporates planning, communicating, staging and delivering the experience (Tynan and McKechnie, 2009), and involves detailed planning and development of strategies and infrastructures to accomplish this (Berman and Thelen, 2004; 
Berry et al., 2002). Consideration of such territorial 'movement' was evident through a range of decision areas, with implications for territorialisation:

"We want to create an environment for people to come to and just enjoy, and on the back of that, learn about [the company]. ... there are many things needed to be done in a short timespan: dealing with the venue, speaking with the venue management, looking at who can accommodate us in terms of our weight and size." (Event Manager, Cosmetics Company).

From initiating the idea, designing the space, creating a 'buzz' (online and offline), to staffing and organising day-to-day practicalities, these different activities brought together a range of people (including creative media and marketing specialists and event management consultancies), to enable the process of territorialisation. This resonates with the more overtly performative aspects of territory as a "domain of practice" (Brighenti, 2010: 610). Thus, respondents from all the established brands interviewed collaborated with a range of additional organisations, contributing to a particular 'refrain':

"We did have other people come on board with us. We had [a public relations company] ... and also [an event management company] who are the guys who came up with the visuals and made it happen. They came with our team and we sit together, once a week, throw ideas at each other. Some of the ideas are absolutely mental; you think, how's that going to happen, but they do make it happen" (Event Manager, Cosmetics Company).

When it came to the operationalisation of the actual pop-up territory, the day-to-day practicalities of organisation and 'material stabilisation' (Kärrholm 2008) required detailed advance planning, given the ephemerality of the territory created. This planning included 
implementing processes of re- and de-territorialisation implicit in the assembly and dismantling of the pop-up activities.

Such re- and de-territorialisation processes were also evident with regard to the annexed milieu, both before and after the staging of the material pop-up activity. Given that the purpose of pop-up can be as much about brand communication/promotion, then making consumers aware of a specific pop-up activity to enable them to take advantage of potential opportunities for brand-related experiences was an important processual aspect, as well as extending the territory (albeit virtually) both spatially and temporally; in this way, perhaps seeking to minimise the effects of the 'unclaspings' (Deleuze and Guattari, 1987), created by the material cessation of the pop-up activity by creating a kind of brand experience 'half-life' relating to the pop-up through social media.

In this regard, all respondents highlighted the importance of social media in generating the 'buzz' that is a defining characteristic of pop-up (Warnaby et al., 2015) and, equally importantly, for monitoring and evaluation purposes during and after the activity. The use and perceived importance - of formal measurement and evaluation mechanisms were evident: the Brand Concept Manager of the Department Store outlined these typical mechanisms as follows:

"Data capture was one measure, sales was another one, footfall was another one, the media and PR coverage whether that was socially or whatever [was] another measure. So, we set ourselves all these measures and, at the end, we go back to those measures and check what we achieved against them".

All the retailers under study used a combination of such methods to evaluate success of the pop-up activities against the objectives set at the start of the process, which were perceived as being largely achieved. In all cases, objectives were orientated towards creating awareness 
(particularly for emergent brands), and/or influencing brand perceptions (for more established brands); the International Marketing Director of the Online Women's Clothing Brand succinctly summed this up, as follows: “...mainly it's for brand awareness to introduce the brand to people who probably don't know us...bring it to the audience that wouldn't necessarily shop with us". From a broader perspective, the Director of a Design Agency working with one of the emergent brands under study, articulated the pop-up's objective in more overtly experiential terms:

"This is about telling a story, it is about a new way a brand identifies what their consumer wants, it's not about getting you to the shop, getting you to see as much stuff as possible so you'll buy it. It is about understand[ing] the relationship with you, and be able to keep in touch with you online and at other locations. What you're doing is building social currency."

We now move to address our third research objective, to evaluate pop-up's potential role in contemporary consumer culture.

\section{Negotiating pop-up's potential role in contemporary consumption processes}

The increasing use of pop-up is one manifestation of the changing landscape of retail consumer culture. Technological innovation is blurring the line between retailers' digital and traditional in-store offerings, bringing both challenges - and opportunities - for how they interact with consumers (Dailey, 2004; Eroglu et al., 2003). The role of the retail store is changing, and whilst a focus on 'selling' remains key, there has been some reorientation towards 'relationship-building' and facilitating a more experientially oriented consumer-brand interaction in an increasingly fluid, multi-channel context (Rayburn and Voss, 2013). Addressing our third research objective, we draw specifically on the 'catalytic' function of 
Deleuze and Guattari's concept of refrain (incorporating rhythm and melody). Rhythm is conceptualised in terms of territorial motifs, characterising the specific expressive qualities of a space, with melody conceptualised as territorial counterpoints, expressing the relationship between territory and external circumstances. From a territorological perspective, in this specific context, the expressive qualities of motif could refer to the extent to which the pop-up territory is positively associated with a particular brand, implied in Brighenti's (2010: 58) highlighting of the "expressive and semiotic" dimensions of territory. This echoes with the fact that pop-up activities can equally be used as much for promotional purposes by communicating organisational/brand values (Warnaby et al., 2015), and facilitating consumer/brand engagement (Kim et al., 2010; Surchi, 2011), as they are for actually selling products.

In this context of temporary brand experience creation, respondents regarded the various elements constituting the interior milieu as crucially important. These included such material dimensions needed to reflect brand values/philosophy and facilitate interactions with the consumer, as well as creating a brand territory through the explicit use of corporate identity communication elements. As Debendetti et al. (2014) suggest, furniture, decorations - as well as activities - provided in the commercial setting, reinforce customers' perceptions of authenticity, which is one of the key attributes of attachment to commercial places. Thus, for example, the Cosmetics Company's London pop-up was a manifestation of its innovative and quirky positioning, in line with its "unique, fun, and feel good" philosophy.

In conceptualising brand experience as a series of subjective, internal consumer responses (e.g. senses, feelings, cognitions) and behavioural responses evoked by brand-related stimuli, Brakus et al. (2009) explicitly highlight branded physical store environments as constituting an important dimension of such experience. As a distinguishing characteristic of pop-up retailing, experiential factors can facilitate positive associations with the organisation/brand. This can arise from specific opportunities for consumers to become 
actively involved in co-creating brand reality, through interacting and creating dialogues with brand representatives and other participants (Vila-López and Rodríguez-Molina, 2013) within the brand-oriented territory. As Smilansky (2009: 4) notes, live brand experiences (such as experientially oriented pop-up activities) "allow the consumer to live, breathe and feel the brand through interactive sensory connections and activities".

Moreover, experiences contribute to enhancing the consumer's emotional connections with the brand across time and space (Moor, 2003). Here, Deleuze and Guattari's concept of melody (through the notion of counterpoint) can refer to how the pop-up 'territory' is more broadly contextualised by brand organisations. As noted above, pop-up is increasingly being used as part of integrated, multi-channel and more creative branding strategies (see Klépierre, 2016), and consequently the spatial-temporal boundaries of the pop-up territory become more amorphous: CEBR (2015) notes, permanent retail stores are already beginning to incorporate some of the temporal elements of pop-up retail to update/complement their product offering.

Our respondents indicated, in particular, that the extensive use of social media served as an additional form of experiential marketing, extending the consumer's temporal brand experience both before and after the pop-up event, as well as creating ongoing communities of interest (see Moor, 2003). This extends pop-up's spatial-temporal territory, facilitating the creation of "floating and multiple" (Brighenti, 2014: 12) brand territories. Implementing social media strategies could also help towards countering the absence of a key attribute fostering place attachment as mentioned by Debendetti et al. (2014), namely familiarity. The inherent ephemerality of pop-up activities could work against creating feelings of familiarity, but social media can be used to partially overcome this, through the notion of the annexed milieu. For example, ongoing communities of interest arising from pop-up activities can be virtual, thereby further expanding the territorial scope through "patterns of relations" (Brighenti, 2010: 57). Pop-up can, therefore, complement existing business strategies by creating a unique 
experience-oriented territory incorporating both physical and virtual aspects that engages customers, and generates a feeling of relevance and interactivity (Kim et al., 2010; Niehm et al., 2007).

This aligns with a key pop-up objective of increasing brand awareness, and enhancing consumers' perceptions of brand values/identity (de Lassus and Anido Freire, 2014; Pomodoro, 2013; Surchi, 2011). Thus, the brand is brought to life by the temporary physical presence of the pop-up store (Warnaby et al., 2015), thereby facilitating commercially-oriented place attachment (Debenedetti et al., 2014). Moreover, the pop-up experience can extend beyond the event itself, with pre- and post-experience processual stages extending the longevity of brand experience. In this context, notions of territorial 'movement' (Deleuze and Guattari, 1987) are highlighted through the more 'fluid' territorological aspects that we expose, to create dynamic socio-spatial relations between the brand and its consumer community, an aspect characterising 'new retailing'.

Given consumers' increasing desire for unique and novel experiences (Grewal et al., 2017) the resulting hedonic elements (consistent with Brighenti's, 2010, notion of territory as an act or practice) define the more ephemeral consumption territory of the pop-up store and can offer consumers a sense of discovery and surprise (Niehm et al., 2007). As Surchi (2011: 260) suggests, a pop-up shop is "a sort of synthesis between communication and selling", thereby valorising the consumption experience and providing a source of competitive advantage for retailers into the future by capitalising on these consumer-driven trends.

\section{Concluding Commentary}

Many retailers are facing challenges in accommodating their strategies and modus operandi to changing industry structural dynamics, which in turn, are propelled by the need to respond to changing consumer needs and behaviours (see Poncin and Mimoun, 2014). Pop-up retailing is 
emerging as an increasingly important part of this 'new retailing' response. In this study, we view pop-up retail activity through a territorological lens as we seek to evaluate its use as a seemingly increasingly necessary aspect of facilitating the consumer's brand experience. Using Deleuze and Guattari's (1987) concept of 'refrain' as a guiding conceptualisation, pop-up's spatial-temporal flexibility and its impact on experiential consumption is highlighted. Focusing on pop-up's dynamic, spatial/temporal nature, we illustrate how pop-up territories can be constituted through the territorialisation of interior, intermediary, exterior and annexed milieus.

Our study contributes to the burgeoning literature on pop-up retailing by considering this increasingly important retail activity from a territorological perspective, highlighting the differences between pop-up and more 'sedentarist' traditional retail formats. From the retailer's point of view, the need for such flexibility has arguably never been greater. To address changing consumer shopping habits, retailers will need to integrate more effectively their instore and online activities, creating novel, interactive hybrid retail concepts (see Gordon, 2004; Kim et al., 2010; Niehm et al., 2007). In so doing, this recognises the need to coordinate the activities of a potentially wide variety of stakeholders, drawing together both material and processual elements in a constrained time period to create a temporary 'territory' to deliver brand experience to consumers; i.e. creating a 'refrain', through the compression and compaction of different milieus.

Given that the boundaries between pop-up and traditional retailing are becoming increasingly blurred (CEBR 2015) as the notion of the 'new retailing' further develops, we suggest that further research could investigate a broader range of activities and decisions involved in the processual stages of designing and implementing pop-up activities within a greater range of contexts. In addition, whilst this research has drawn on pop-up activities that were deemed successful by those responsible for their implementation, further research to investigate the criteria by which success is determined is needed. This would potentially be 
contingent on the type(s) of organisations in question. For example, in relation to one of the criteria used to select cases in this study: to what extent does the definition of what constitutes 'success' vary between emergent and established brands given the fact that pop-up could be used to achieve differing objectives? Such research would increase our understanding of the actual utility of pop-up activity, which has been somewhat neglected to date.

In this paper, we have focused on the retailer/brand perspective on pop-up retailing. However, this only constitutes one dimension of the relationships that pop-up seeks to foster, and more extensive research is required to consider these issues from the consumer's perspective in order to ascertain whether some of the conclusions drawn here are applicable. Finally, we have highlighted the spatial aspects of pop-up through the milieu concept, and we suggest building on this, by taking a more overtly locational perspective (e.g. Harris 2015) to examine critical assessments of the pop-up concept in terms of its implications for the use of retail space - and its associated 'territorialisation' - in wider spatial contexts, such as urban shopping destinations.

\section{References}

Antéblian B, Filser M and Roederer C (2014). Consumption experience in retail environments: A literature review. Recherche et Applications en Marketing (English Edition) 28(3):82-109.

Arnould E J, Linda L P and Zinkhan G (2004) Consumers. New York: McGraw- Hill/Irwin.

Beekmans J and de Boer J (2014) Pop-Up City: City-Making in a Fluid World. Amsterdam: BIS Publishers. 
Berman B and Thelen S (2004) A guide to developing and managing a well-integrated multichannel retail strategy, International Journal of Retail \& Distribution Management 32 (3): $147-156$.

Berry L L, Carbone L P and Haeckel S H (2002) Managing the total customer experience. Sloan Management Review 43: 85-89.

Bladen C, Kennell J, Abson E and Wilde N (2012) Events Management: An Introduction. Abingdon: Routledge.

Brakus J J, Schmitt B H and Zarantonello L (2009) Brand Experience: What Is It? How Is It Measured? Does It Affect Loyalty? Journal of Marketing 73:52-68.

Brighenti A M (2010) On territorology: Towards a general science of territory. Theory, Culture \& Society 27(1): 52-72.

Brighenti A M (2014) Mobilizing territories, territorializing mobilities. Sociologica 2014(1): $1-25$.

Brown S (1987) A perceptual approach to retail agglomeration. Area 19(2): 131-140.

Butler S (2018) Apocalypse now for Britain's retailers as low wages and the web cause ruin The Observer, 18 February. 60-61.

Campbell J L, Quincy C, Osserman J and Pedersen, O (2013) Coding in-depth semi-structured interviews. Problems of unitization and inter-coder reliability and agreement. Sociological Methods Research 42 (3): 294-320.

Centre for Economics and Business Research [CEBR] (2014). Britain's Pop-up Retail Economy 2014. London CEBR. Available at: https://ee.co.uk/content/dam/everythingeverywhere/Newsroom/PDFs\%20for\%20newsroom/EE\%20PopUp_Retail_Economy_Report.pdf (accessed on: 18 August 2015). 
Chatzidakis A, McEachern M and Warnaby G (2018) Consumption in and of space and place: Introduction to the special issue. Marketing Theory 18(2): 149-153.

Crang M (2005) Analyzing qualitative materials. In: Flowerdew R and Martin M (eds). Methods in Human Geography: A Guide for Students Doing a Research Project, Upper Saddle River, NJ: Prentice Hall, pp. 218-232.

Dailey L (2004) Navigational web atmospherics: explaining the influence of restrictive navigation cues. Journal of Business Research 57 (7): 795-803.

De Lassus C, Anido Freire N (2014) Access to the luxury brand myth in pop-up stores: A netnographic and semiotic analysis. Journal of Retailing and Consumer Services. 21: $61-68$

Debenedetti A, Oppewal H and Arsel Z (2014) Place attachment in commercial settings: A gift economy perspective. Journal of Consumer Research 40(5): 904-923.

Decrop, A (1999) Triangulation in qualitative tourism research. Tourism Management 20(1): $157-161$.

Deleuze G and Guattari, F (1987) A Thousand Plateaus: Capitalism and Schizophrenia (trans. B. Massumi). London: The Athlone Press.

Denzin, N K (1978) The Research Act: A Theoretical Introduction to Sociological Methods. New York: McGraw-Hill.

Donlan L and Crowther P (2014) Leveraging sponsorship to achieve consumer relationship objectives through the creation of 'marketing spaces': An exploratory study. Journal of Marketing Communications 20(4): 291-306.

Eisenhardt K M and Graebner M E (2007) Theory Building From Cases: Opportunities and Challenges. Academy of Management Journal 50(1): 25-32. 
Eisenhardt K M (1989) Building theories from case study research. Academy of Management Review 14(4): 532-550.

Eroglu S A, Machleit K and Davis L M (2003) Empirical testing of a model of on-line store atmospherics and shopper response. Psychology \& Marketing 20 (2): 139-150.

Ferreri M (2015) The seductions of temporary urbanism. Ephemera: Theory \& Politics in Organization 15 (1): 181-191.

Ferreri M (2016) Pop-up shops as an interruption in (post-)recessional London. In Shirley J and Lindner C (eds.) Cities Interrupted: Visual Culture and Urban Space. London: Bloomsbury Academic, pp. 141-157.

Gephart R P (2004) Qualitative Research and the Academy of Management Journal. Academy of Management Journal 47(4): 454-462.

Grewal D, Roggeveen A L and Nordfält J (2017) The future of retailing. Journal of Retailing. 93(1): 1-6.

Grosz E A (2008) Chaos, Territory, Art: Deleuze and The Framing of The Earth. New York: Columbia University Press.

Harris E (2015) Navigating popup geographies: Urban space-times of flexibility, interstitiality and immersion. Geography Compass 9(11): 592-603.

Hracs B J and Jansson J (2017) Death by streaming or vinyl revival? Exporing the spatial dynamic and value creating strategies of independent record shops in Stockholm. Journal of Consumer Culture https://doi.org/10.1177/1469540517745703

Kärrholm M (2007) The materiality of territorial production. Space and Culture 10(4): 437453. 
Kärrholm M (2008) The territorialisation of a pedestrian precinct in Malmö. Urban Studies 45: 1903-1924.

Kärrholm M (2012) Retailising Space: Architecture, Retail and the Territorialising of Public Space. Farnham: Ashgate Publishing.

Kim H, Fiore A M, Niehm, L S and Jeong M (2010) Psychographic characteristics affecting behavioural intentions towards pop-up retail. International Journal of Retail \& Distribution Management 38 (2): 133-154.

Klépierre (2016) Pop-up Stores: Conquering a New Frontier of Brand Expression, Klepeirre, Paris. Available at:

http://www.klepierre.com/content/uploads/2016/02/White_Paper_Pop-up_Stores.pdf (accessed 5 January 2017)

Melewar T C (2003) Determinants of the corporate identity construct: A review of the literature. Journal of Marketing Communications 9(4): 195-220.

Moor E (2003) Branded spaces: The scope of 'new marketing'. Journal of Consumer Culture 3(1): 39-60.

Niehm L S, Fiore A M, Jeong M and Kim H J (2007) Pop-up retail's acceptability as an innovative business strategy and enhancer of the consumer shopping experience. Journal of Shopping Center Research 13(2): 1-30.

Overdiek A (2018) Opportunities for slow fashion retail in temporary stores. Journal of Fashion Marketing and Management 22(1): 67-81.

Pantano E and Viassone M (2014) Demand pull and technology push perspective in technology-based innovations for the points of sale: The retailers evaluation. Journal of Retailing and Consumer Services, 21: 32-47. 
Pomodoro S (2013) Temporary retail in fashion system: an explorative study. Journal of Fashion Marketing and Management, 17(3): 341 - 352.

Poncin I and Mimoun M S B (2014) The impact of "e-atmospherics" on physical stores Journal of Retailing and Consumer Services 21(5): 851-859.

Puccinelli N, Goodstein R C, Grewal D, Price R, Raghubir P and Stewart D (2009) Customer experience management in retailing: understanding the buying process. Journal of Retailing 85(1): 15-30.

Rayburn S W and Voss K E (2013) A model of consumer's retail atmosphere perceptions. Journal of Retailing and Consumer Services 20 (4): 400-407.

Ritzer G and Miles S (2019) The changing nature of consumption and the intensification of McDonaldization in the digital age. Journal of Consumer Culture 19(1): 3-20.

Russo Spena T, Caridà A, Colurcio M and Melida M (2012) Store experience and co-creation: the case of temporary shop. International Journal of Retail \& Distribution Management 40(1): 21-40.

Schwarzer M (2013) “The emergence of container urbanism” Places Journal, February, Available at: https://placesjournal.org/article/the-emergence-of-container-urbanism/ (accessed on 29 March 2018).

Sherry J F Jr (1990) A sociocultural analysis of a Midwestern American flea market. Journal of Consumer Research, 17: 13-30.

Smilansky S (2009) Experiential Marketing: A Practical Guide to Interactive Brand Experiences. London: Kogan Page.

Spiggle S (1994) Analysis and interpretation of in qualitative data in consumer research Journal of Consumer Research, 21(3): 491-503. 
Stake R (1998) Case studies. In: Denzin N K and Lincoln Y S (eds). Strategies of Qualitative Inquiry. London: Sage. pp. 86-109.

Surchi M (2011) The temporary store: a new marketing tool for fashion brands. Journal of Fashion Marketing and Management, 15 (2): 257-270.

Tum J, Norton P and Wright J (2006) Management of Event Operations. Oxford, Burlington, MA: Elsevier/Butterworth-Heinemann.

Tynan C and McKechnie S (2009) Experience marketing: a review and reassessment. Journal of Marketing Management, 25(5-6): 501-517.

Vandenberghe F (2007) Avatars of the Collective: A Realist Theory of Collective Subjectivities. Sociological Theory 25: 295-324.

Verhoef P C, Lemon K N, Parasuraman A, Roggeveen A, Tsiros M and Schlesinger L A (2009) Customer experience creation: determinants, dynamics and management strategies. Journal of Retailing 85(1): 31-41.

Warnaby G, V Kharakhorkina, C Shi and M Corniani (2015) Pop-up retailing: Integrating objectives and activity stereotypes. Journal of Global Fashion Marketing, 6(4): 303316.

Warnaby G and C Shi (2018) Pop-up Retailing: Managerial and Strategic Perspectives. Heidelberg: Springer

Wood Z (2017) As Amazon opens a 'guerrilla shop', has the internet beaten high streets?' The Observer, 19 November, 30.

Yin R K (2014). Case Study research: Design and methods (5th edn) Thousand Oaks CA: Sage Publications. 